\title{
A vivência da sexualidade da mulher estomizada
}

Recebido em: 23/08/2013

Aprovado em: 14/06/2014

\author{
Antônio Dean Barbosa Marques ${ }^{1}$ \\ Jessica Suyanne Gomes Silva² \\ Leidinar Cardoso Nascimento ${ }^{3}$ \\ Inez Sampaio Nery ${ }^{4}$ \\ Maria Helena Barros Araújo Luz
}

Resumo: Objetivou-se conhecer como a mulher estomizada vivencia sua sexualidade. Estudo de natureza qualitativa na perspectiva da história oral de vida, no qual participaram 10 mulheres cadastradas em um Centro de Saúde de Teresina, no mês de junho de 2012. Emergiram quatro categorias: o significado da sexualidade; a vivência da sexualidade; o apoio do parceiro no processo de aceitação do estoma e ser mulher e conviver com o estoma. As mulheres estomizadas vivenciam sua sexualidade dentro de um universo repleto de sentimentos de medo, de vergonha e de dúvidas.

Descritores: Estomia, Sexualidade, Gênero, Enfermagem.

\section{The sexuality's experience of stomized women}

Aimed at learning about how stomized women experience their sexuality. Qualitative nature study of from the oral perspective story of life, attended by 10 women enrolled in a the Health Center of Teresina, in June 2012. Four categories emerged: the meaning of sexuality, the experience of sexuality; spousal support in the process of acceptance of the stoma and being a woman and live with the stoma. Ostomized women experience their sexuality in a universe filled with feelings of fear, shame and doubt.

Descriptors: Ostomy, Sexuality, Gender, Nursing.

\section{La experiencia de la sexualidad de la mujer con ostomía}

Se objetivó conocer acerca de cómo la mujer con ostomía experimenta su sexualidad. Estudio de naturaleza cualitativa en la perspectiva de la historia oral de vida, en el cual participaron 10 mujeres con catastro en el Centro de Salud de Teresina, en junio de 2012. Emergieron cuatro categorías: el significado de la sexualidad, la vivencia de la sexualidad, el apoyo del cónyuge en el proceso de aceptación del estoma y ser mujer y convivir con el estoma. Las mujeres portadoras de ostomías experimentan su sexualidad dentro de un universo repleto de sentimientos de miedo, de vergüenza y de duda.

Descriptores: Ostomía, Sexualidad, Género, Enfermería.

\section{INTRODUÇÃO}

A estomia é representada de forma ambígua pelos indivíduos estomizados que, de certo modo, sentem-se beneficiados pela obtenção da cura ou melhoria de uma doença ou acidente. Entretanto, este procedimento gera inquietação, dúvida e questionamentos sobre suas novas possibilidades de bem-estar, interação social e qualidade de vida, frente a essa nova condição física a qual resulta também em alteração da imagem corporal(1).

Devido às diversas mudanças enfrentadas, pessoas estomizadas vivenciam sentimentos de desorganização emocional que culminam em reclusão social, tudo relacionado à questão da autoimagem. A autoimagem pode ser definida como a representação mental que alguém faz de si mesmo; a maneira como sente o próprio corpo está intimamente relacionada com a autoestima ${ }^{2}$. A criação de um estoma gera ruptura da imagem corporal, ocasionando sentimentos discriminatórios de estigma.

Atualmente, a busca pela perfeição estética e enquadramento nos padrões de beleza tem levado uma parcela significativa da população feminina a submeterem-se às mais diversas técnicas e procedimentos. Nesse contexto, ser "mulher" e aceitar-se com um estoma, seja ele definitivo ou temporário, no qual a parte do seu íntimo encontra-se exposto, é contrapor-se, mesmo que de forma involuntária, aos padrões culturalmente aceitos ${ }^{(3)}$.

As alterações na imagem corporal provocam, na maioria dos estomizados, dificuldades relacionadas à sexualidade (4). Essas disfunções ocorrem pelo sentimento de vergonha frente ao parceiro devido à alteração da imagem corporal, ocasionando redução ou perda do desejo, dor durante o ato sexual, disfunções ejaculatórias ou de ereção( ${ }^{(5)}$.

O tema sexualidade faz parte de uma das prioridades das políticas públicas de atendimento à mulher. No entanto, a abordagem centra-se no diagnóstico e no tratamento de problemas de saúde, não necessariamente abarcando toda a complexidade que o tema exige. Ainda mais, ressalta-se que $o$ atendimento, dá-se individualmente, nas consultas ginecológicas a partir da demanda espontânea de cada mulher que, muitas vezes, restringe-a ao campo delimitado da 
doença e/ou da restauração do funcionamento dos órgãos ${ }^{(6)}$.

Sabe-se que a realização de uma estomia gera mudanças significativas no cotidiano da pessoa, mudanças essas que exigem adaptação do estomizado à nova fase que vivencia. Entre essas alterações, está a sexualidade do estomizado, assunto difícil de ser abordado tanto por quem vivencia a estomia como pelos profissionais de saúde. O estomizado acredita que a temática da sexualidade é uma questão secundária, sendo a mulher mais afetada por conta das alterações da autoimagem.

Devido à complexidade da assistência ao estomizado, é necessária uma abordagem multidisciplinar tanto ao paciente como para a família diante desse novo processo. Dessa forma, o estudo visa a uma melhor compreensão da subjetividade humana do estomizado em relação à vivência da sexualidade pela mulher.

Baseado neste contexto, este estudo objetivou conhecer como a mulher estomizada vivencia sua sexualidade.

\section{METODOLOGIA}

Estudo de natureza qualitativa na perspectiva da história oral de vida."A história oral de vida possibilita superar a mera aquisição de dados em favor da possibilidade de uma visão mais subjetiva das experiências dos depoentes"(7:85).

A pesquisa teve como cenário o Centro Integrado de Saúde Lineu Araújo (CISLA), que pertence à Fundação Municipal de Saúde (FMS) de Teresina-PI. Os sujeitos da pesquisa foram 10 mulheres, que atenderam aos critérios de inclusão, que foram: mulheres maiores de 18 anos com estomia intestinal definitiva, com no mínimo um ano de realização da cirurgia, cadastradas no CISLA, que apresentaram condições físicas e emocionais para participarem do estudo.

As entrevistas foram realizadas durante o mês de junho de 2012, sendo as falas analisadas de acordo com os passos específicos da história oral: transcrição na integra, textualização e transcriação ${ }^{7}$.

Durante a transcrição foram preservados os erros tanto dos colaboradores como dos entrevistadores, como forma de garantir a qualidade da entrevista. O passo seguinte foi à textualização na qual foram eliminadas as perguntas de forma que o texto passasse a ser dominante do narrador. E por último foi feito a transcriação, no qual o texto foi apresentado em sua versão final aos colaboradores.

O estudo foi aprovado pelo Comitê de Ética em Pesquisa (CEP) da Faculdade NOVAFAPI, com o protocolo do CAAE n० 01138312.2.0000.5210. Todas as colaboradoras que participaram do estudo assinaram o Termo de Consentimento Livre e Esclarecido (TCLE).

\section{RESULTADOS}

O estudo foi composto por 10 colaboradoras que atenderam aos critérios de inclusão. Em relação à faixa etária das mulheres, variou de 29 anos a 50 anos de idade. 7 mulheres eram solteiras e 3, casadas. Quanto ao tempo de convívio com o estoma, ocorreu uma variação de 01 ano a 24 anos. A maioria dos estomas era do tipo colostomia, sendo apenas 2 ileostomias. Quanto à causa do estoma, houve predominância de neoplasia. Conforme pode ser observado na Tabela 01.
Tabela 01 - Caracterização das colaboradoras do estudo. Teresina, Piauí, 2012.

\begin{tabular}{|c|c|c|c|c|c|}
\hline Colaborador & Idade & $\begin{array}{c}\text { Estado } \\
\text { civil }\end{array}$ & $\begin{array}{c}\text { Tempo } \\
\text { de } \\
\text { estomia }\end{array}$ & $\begin{array}{l}\text { Tipo de } \\
\text { estomia }\end{array}$ & $\begin{array}{c}\text { Origem do } \\
\text { estoma }\end{array}$ \\
\hline C 01 & 33 & Solteira & 05 anos & Colostomia & $\begin{array}{c}\text { Fístula } \\
\text { enterocutânea }\end{array}$ \\
\hline $\mathrm{C} 02$ & 32 & Solteira & 17 anos & Ileostomia & Adenocarcinoma \\
\hline $\mathrm{C} 03$ & 29 & Casada & 01 ano & Ileostomia & Adenocarcinoma \\
\hline $\mathrm{CO} 04$ & 38 & Casada & 03 anos & Colostomia & Adenocarcinoma \\
\hline C 05 & 53 & Solteira & 24 anos & Colostomia & Adenocarcinoma \\
\hline C 06 & 38 & Solteira & 01 ano & Colostomia & $\begin{array}{c}\text { Trauma de } \\
\text { cólon }\end{array}$ \\
\hline C 07 & 34 & Solteira & 10 anos & Colostomia & $\begin{array}{c}\text { Doença de } \\
\text { Crohn }\end{array}$ \\
\hline C 08 & 50 & Solteira & 02 anos & Colostomia & $\begin{array}{c}\text { Doença de } \\
\text { Crohn }\end{array}$ \\
\hline C 09 & 48 & Casada & 03 anos & Colostomia & Câncer anal \\
\hline C 10 & 49 & Solteira & 04 anos & Colostomia & $\begin{array}{c}\text { Fístula reto } \\
\text { vaginal }\end{array}$ \\
\hline
\end{tabular}

Após a análise das entrevistas das colaboradoras, houve agrupamento das ideias significativas que atenderam aos objetivos da pesquisa, possibilitando manifestarem as suas vivências em quatro categorias: o significado da sexualidade; a vivência da sexualidade; o apoio do parceiro no processo de aceitação do estoma e ser mulher e conviver com o estoma. Cada categoria apesentam fragmentos das falas que deram sustentação e se encontram identificados com a letra (C), de colaborador e número na sequência cronológica em que as entrevistas foram realizadas.

\section{DISCUSSÃO}

\section{O significado da sexualidade}

A sexualidade é parte integrante e fundamental do processo de viver humano, sofrendo influência de diversos fatores que contribuem significativamente para o bem-estar das pessoas ${ }^{8}$. Nos relatos, o significado de sexualidade é relacionado a sentimentos e à necessidades fisiológicas.

"A sexualidade é algo divino, é algo que faz parte do meu corpo... minha sexualidade é uma benção que Deus me deu. Pra mim a sexualidade está voltada para a procriação" (C 02)

"[...] É qualidade de vida, é uma coisa que faz parte da vida da gente né? do dia a dia [...]" (C 03)

“[...] Em meu pensamento era só pra satisfazer um dom que a gente traz, que Deus da né? que sente... Sei lá aquela vontade de saciar o desejo carnal" (C 10)

A sexualidade caracteriza-se como um aspecto de nossa personalidade presente em todos os momentos de nossa vida, englobando não somente a genitália, mas também aspectos biológicos, psicobiológicos e sociais ${ }^{(9)}$.

Os depoimentos das colaboradoras demonstram a valorização e a importância que atribuem à sexualidade/sexo, sendo visto por elas como algo essencial para a vida e para a reprodução. Mobilizando sentimentos e associando-se ao poder criador, isto é, possibilitando a procriação da espécie. 


\section{A vivência da sexualidade}

A vivência da sexualidade é de extrema importância, esta poderá ter reflexos positivos, negativos, ou até neutros durante o processo de viver humano. 0 estoma intestinal gera alteração da imagem corporal, influenciando em diversos aspectos da vida da pessoa, inclusive na esfera sexual ${ }^{(8)}$.

"Pra mim é complicado, pois eu vivo na castidade, por opção própria [...] isso não significa que eu não sinta desejo, pois a castidade foi uma opção de vida [...] fui muito roubada de mim na minha infância e adolescência, tive uma experiência sexual na minha infância, eu tive a minha pureza praticamente roubada [...] tive uma experiência relacionada à masturbação e eu não era feliz, minha área psicológica não era algo livre, não era saudável e hoje eu sou completamente liberta relacionada a essa questão, hoje sou mais feliz e mais realizada. "(C 02)

"Eu tinha até dificuldade de manter relação com homem, porque eu sempre fui uma pessoa assim envergonhada [...]" (C 07)

Os colaboradores demonstraram que as disfunções sexuais são consequências da própria origem do estoma, acarretando alterações nos órgãos genitais. Além disso, aqueles que não possuíam um relacionamento sólido tenderam a ficar só, pois vivenciaram sentimentos de vergonha, reprimindo o desejo sexual e até mesmo desinteresse sexual. Mesmo aquelas que não mantiveram mais relação após o estoma referiram sentir desejo.

"Minha vida sexual modificou porque eu tinha uma expectativa de ter filhos, aí esse sonho teve que ser retardado, mas intimamente sou normal eu não sinto nenhuma interferência, após as relações eu não sinto dor, não sinto nenhum tipo de problema. Não senti nenhum tipo de constrangimento durante a primeira relação." (C 03)

"Após a realização da estomia a minha vida sexual não mudou em nada ficou do mesmo jeito, quem sabe mudou até pra melhor né?!." (C 04)

As mulheres vivenciam sua sexualidade das mais variadas formas, isso nos faz compreender que o vivido mostra-se em diferentes facetas, em uma determinada mesma situação, evidenciando modos distintos de uma disfunção comum a todas.

O apoio do parceiro no processo de aceitação do estoma

A estomia ocasiona profundas mudanças na vida das pessoas e seus familiares, manifestando através de desajustes físicos, emocionais, sociais e familiares ${ }^{(10)}$. $O$ apoio da família e do parceiro é essencial para o desenvolvimento de atitudes positivas frente à doença e à nova situação, tornando mais fácil e rápido o processo de recuperação, a adaptação, o retorno às atividades diárias, inclusive quanto à vivência da sexualidade ${ }^{(11)}$.

Algumas mulheres relataram ser de fundamental importância a participação do parceiro no processo de aceitação do estoma, devido às suas qualidades, ofertando apoio e ajudando no redescobrir da sexualidade, favorecendo-lhes a adaptação e/ou a aceitação de sua nova condição de vida.

“[...] no começo eu tive depressão, preconceito, mas graças a Deus eu tive muita força [...] tive muito apoio do meu esposo [...] o meu esposo em relação à sexualidade foi uma peça chave para a minha recuperação e para o meu redescobrir da sexualidade..." (C 04)
"[...] O meu esposo me deu todo o apoio, não foi por isso que nos separamos, foram por outros problemas" (C 05)

A qualidade do relacionamento entre os parceiros é indicador das características de vida sexual pós-estoma. A vivência da sexualidade pelo parceiro do estomizado é caracterizada por mecanismos de períodos de crises, que resultam em enfrentamento geralmente negativo, devido à falta de apoio durante as intervenções dos profissionais ${ }^{(8)}$.

"[...] Morava com o pai dos meus meninos, e depois que eu fiz isso aqui (apontando para o estoma) ele saiu de dentro de casa... faz um ano já!" (C 06)

"[...] Tinha um namorado na época... esse namorado, quando o médico conversou com ele sobre o meu estado e tudo ele já ficou diferente, já me tratando como uma pessoa inválida achando que tudo faz mal, que tudo dói e tudo é difícil e a gente mesmo não aceita pelo menos eu, porque estou com 02 anos e ainda não aceito, eu tenho vergonha..." (C 08)

Vivenciar qualquer mudança não é algo fácil, principalmente se ocorrem mudanças de caráter definitivo. $O$ apoio de familiares e parceiros é indispensável para o processo de aceitação e reabilitação do estomizado, pois são eles que se encontram presentes desde o aparecimento dos primeiros sinais e sintomas à confecção do estoma, oferecendo suporte para minimizar o sofrimento.

\section{Ser mulher e conviver com o estoma}

De acordo com as colaboradoras, o processo de conviver com a estomia interfere na imagem corporal, acarretando alterações na autoestima, na autoimagem e no autoconceito. A estomia é vista pelas colaboradoras como alienação do próprio corpo, devido à invasão bolsa/estoma e às alterações corporais.

"Se não tiver bem psicologicamente a gente sofre muito com a questão da autoestima, porque para uma mulher jovem, vaidosa, acostumada a vestir diversos tipos de roupa... fica inadequado com a presença da colostomia do lado..." (C 03)

"[...] em termo de roupa você muda totalmente, há não ser que você queira mostrar que tem um estoma..." (C 08)

"[...] não sou mais vaidosa, não me sinto bonita, não me sinto mais a vontade... eu gostava muito de andar vestida de jeans, bermuda jeans, calça jeans [...] hoje em dia só visto um gibão..." (C 10)

“[...] vivo a minha vaidade feminina de acordo com a minha situação de vida, na verdade eu uso o que é adequado a mim" (C 02)

O equipamento coletor modifica o modo de se vestirem, utilizando, sobretudo, roupas largas que têm como propósito ocultar o uso da bolsa, entretanto esse tipo de estratégia contribui para o prejuízo na estética corporal, consequentemente, na diminuição da autoestima ${ }^{(4)}$.

A pessoa estomizada se depara com uma nova situação, uma vez que a imagem corporal construída durante toda a sua vida é quebrada com a presença de um dispositivo na parede abdominal em que fezes ou urina são coletadas continuamente sem controle, significando a perda do controle esfincteriano e, consequentemente, gerando insegurança, medo, vergonha e isolamento social, necessitando assim de suporte para adaptação(5). 


\section{CONCLUSÃO}

A sexualidade é uma temática que requer cuidado ao ser abordada, por ser tratar de um assunto íntimo e possuir uma multiplicidade de significados que, por sua vez, encontram-se ligadas a diversos fatores. A discussão da sexualidade articulada à relação sexual e aos problemas a ela relacionados demonstrou que as colaboradoras sofreram modificações significativas no modo de vivenciarem a sexualidade.

As mulheres estomizadas vivenciam sua sexualidade dentro de um universo repleto de sentimentos de medo, de vergonha, de dúvidas e de limitações criadas por elas mesmas e/ou pelo próprio estoma. Entretanto, o estudo revela também mulheres felizes, otimistas, sonhadoras, que consideram ser possível viverem sua sexualidade de maneira mais ampla, sem ou com menos restrição.
Fica evidenciado que a atenção à sexualidade da mulher estomizada requer esforços dos profissionais de saúde, destacando o enfermeiro, para melhorar a qualidade da assistência prestada. Para isso, é necessário o engajamento não só de profissionais, mas também dos parceiros, a fim de amenizar o impacto ocasionado pelo estoma e facilitar o processo de aceitação.

A sexualidade como forma de expressão natural do ser humano ainda é um assunto pouco valorizado na prática de assistência à saúde. Revelando a necessidade de mais estudos na área de saúde e enfermagem sobre essa temática, pois sempre terá algo a ser descoberto.

\section{Referências}

1. Nascimento CMFS. A vivência da sexualidade pelo estomizado: um estudo de enfermagem na abordagem fenomenológica [dissertação]. Teresina (PI): Universidade Federal do Piauí; 2010.

2. Matos D, Saad SS, Fernandes LC. Guias de medicina ambulatorial e hospitalar de coloproctologia. São Paulo: Manole; 2004.

3. Anhaia AS, Vieira JC, Vieira AMLM. A mulher e o estoma: implicações na vida diária. Rev. Estima. 2007; 5(4): 20-5.

4. Silva AL, Shimizu HE. O significado da mudança no modo de vida da pessoa com estomia intestinal definitiva. Rev. Latino-am. Enferm. 2006; 14(4): 483-90.

5. Nascimento CMS, Trindade GLB, Luz MHBA, Santiago RF. Vivência do paciente

estomizado: uma contribuição para a assistência de enfermagem. Texto Contexto

Enferm. 2011; 20(3): 357-64.
6. Trindade WR, Ferreira MA. Sexualidade feminina: questões do cotidiano das mulheres. Rev. Texto Contexto Enferm. 2008; 17(3): 417-26.

7. Meihy JCSB, Holanda F. História oral: como fazer, como pensar. São Paulo: Contexto; 2007.

8. Paula AMB. Representações sociais sobre a sexualidade de pessoas estomizadas: conhecer para transformar [tese]. São Paulo (SP): Universidade de São Paulo; 2008.

9. Melo AS, Carvalho EC, Pelá NTR. A sexualidade do paciente portador de doenças onco-hematológicas. Rev. Latino-am. Enferm. 2006; 14(2): 227-32.

10. Sousa CF, Brito DC, Branco MZPC. Depois da colostomia... vivências das pessoas portadoras. Enferm foco. 2012; 3(1):12-15.

11. Silva AL, Shimizu HE. A relevância da rede de apoio ao estomizado. Rev. Bras. Enferm. 2007; 60(3): 307-11. 